\title{
PROTOCOLO DE EMERGÊNCIA, RACIONALIDADE LIMITADA E DEFERÊNCIA: APORTES PARA DECISÕES PROFERIDAS NO CENÁRIO DA PANDEMIA DO NOVO CORONAVÍRUS.
}

\author{
André Ladeira da Rocha Leão ${ }^{1}$ \\ Paulo Marcio Reis Santos ${ }^{2}$
}

\begin{abstract}
Resumo: A partir da crítica à concentração de poderes no Executivo americano após o onze de setembro de 2001, procura-se analisar a melhor postura hermenêutica para decisões proferidas em ambientes de incerteza, seja empírica ou normativa. Para contornar tais questões, defende-se uma atitude pragmática que leve em consideração o contexto decisório, as informações empíricas disponíveis e as capacidades institucionais, para apresentar uma metateoria adequada a oferecer opções coerentes que representem soluções objetivas para cenários de incerteza. Com espeque no método dedutivo, revisão bibliográfica e documental, almeja-se oferecer aportes para decisões proferidas no período da pandemia do novo coronavírus.
\end{abstract}

Palavras-chave: Capacidades institucionais; Deferência; Incerteza; Pragmatismo; Racionalidade limitada.

\section{EMERGENCY PROTOCOL, LIMITED RATIONALITY AND DEFERENCE: CONTRIBUTIONS TO DECISIONS MADE IN THE CORONAVIRUS PANDEMIC SCENARIO.}

\begin{abstract}
Based on the criticism of the concentration of powers in the American executive power after September 11, 2001, an attempt is made the best hermeneutical posture for decisions made in environments of uncertainty, whether empirical or normative. A pragmatic attitude is advocated that takes into account the decision-making context, available empirical information and the institutional capacities, in order to define the appropriate meta-theory to offer a solution that is coherent for uncertainty scenarios. With a focus on the deductive method, with bibliographical and documental review, the aim is to provide input for decisions made during the coronavirus pandemic period.
\end{abstract}

Keywords: Institutional capacities; deference; uncertainty; pragmatism; bounded rationality.

\section{INTRODUÇÃO.}

\footnotetext{
${ }^{1}$ Juiz de Direito do Tribunal de Justiça do Estado de Minas Gerais. Mestrando em Direito Público no PPGD FUMEC. Rua Congonhas, n.259, ap. 401, São Pedro, Belo Horizonte, MG, CEP 30.330-016. E-mail: ladrleao@gmail.com.

${ }^{2}$ Sócio fundador da PMRS Advocacia e Consultoria. Doutor e Mestre em Direito pela Universidade Federal de Minas Gerais. Professor no Mestrado e na Graduação em Direito da Universidade FUMEC. Rua Paulista, n.801, ap. 502, Fernão Dias, Belo Horizonte, MG, CEP 31910-532. E-mail: paulo.marcio@ fumec.br.
}

Teorias do Direito e Realismo Jurídico | e-ISSN: 2525-9601 | Encontro Virtual | v. 7 | n. 2 | p. $01-17$ | Jul/Dez. 2021. 
Em artigo de grande repercussão, Stephen Holmes (HOLMES, 2009) descreveu a cena trágica na qual sua filha sofreu uma queda que lhe provocou traumatismo craniano. Socorrida às pressas para o Hospital, a equipe médica iniciou o atendimento. Todos os passos do protocolo de emergência foram meticulosamente observados para evitar erros. A comunicação foi rápida, repetida, na forma das precauções para evitar equívocos causados pela desorientação momentânea.

Stephen Holmes (HOLMES, 2009) mirava os abusos decorrentes das normas de exceção que concentraram poderes no Executivo para combater o terrorismo nos Estados Unidos após o onze de setembro de 2001, desprestigiando-se direitos fundamentais e estatutos que limitavam os poderes do Presidente. Em suma, questionava o autor se seria preciso conferir poderes excepcionais ao governo para enfrentar o terrorismo.

A presente proposta de reflexão não trará a desejada solução sobre quem está certo, a raposa ou o porco espinho (DWORKIN, 2018), mas tentará oferecer subsídios úteis e uma abordagem racional para uma modelagem decisória no cenário pandêmico, considerados os milhares de processos em andamento no Brasil.

Se no plano filosófico, para algumas questões, pode-se defender dicotomias entre o certo e o errado, como: a escravidão é errada; a condenação de um inocente é errada; a tortura de um bebê é errada (DWORKIN, 2010); etc.., fora de tal plano de abstração, é preciso oferecer respostas que sejam compatíveis com a incerteza e subjetividade inerentes ao fenômeno jurídico e que se situam em outro plano de abstração.

O que se pretende demonstrar é a pertinência da crítica de Holmes (HOLMES, 2009) ao sustentar que soluções nada racionais, intuitivas e enviesadas são comumente proferidas e percebidas como inerentes aos cenários de incerteza, tais como as decisões no Brasil que restringiram a deambulação das pessoas durante o período pandêmico. Sustenta-se que, mesmo nesse cenário, deve-se seguir um "protocolo de emergência".

Nesse sentido, assim na medicina como no direito, não obstante todas as dificuldades e da premência de soluções criativas e rápidas, há sempre um protocolo que procura evitar erros de julgamento impostos pela necessidade de se tomarem decisões complexas cujos contornos são imprevisíveis, em ambientes com poucas informações.

No contexto brasileiro, tal crítica pode ser um caminho para se reconhecer que, mesmo em cenários complexos e de grande incerteza empírica, haverá sempre um protocolo a seguir, 
é dizer, restrições legais e institucionais para a atuação dos gestores em situações nas quais não há informações suficientes sobre as consequências sistêmicas ou mesmo sobre qual a melhor opção decisória.

Aproveitando-se de tal crítica, o presente trabalho pretende analisar a contribuição da perspectiva pragmática para a solução de complexas questões decididas em contextos adversos como o são as decisões sobre medidas adotadas no cenário pandêmico atual.

Destacar-se-ão recentes alterações normativas que procuraram traduzir um "protocolo" para decisões proferidas em ambiente de incerteza visando reduzir o erro e produzir soluções que propiciem melhores perspectivas sistêmicas.

Se nem sempre é possível obter-se a resposta certa e apontar a direção a seguir, talvez seja possível reduzir a incerteza e diminuir os custos do erro, a partir das margens de atuação que considerem as consequências das opções decisórias. Para isso, mais que alterações legislativas, é necessária alteração do comportamento dos decisores e controladores que, cientes de suas limitações, devem buscar soluções sensatas mais próximas da realidade e do contexto decisório. É o que o presente trabalho pretende sugerir.

O primeiro tópico tratará da abordagem padrão para casos difíceis, que parte da perspectiva de uma racionalidade ideal e procura delimitar o espaço de discricionariedade dos decisores comparando as condições reais dos tomadores de decisão às condições ideais, forte na noção de ideia regulativa. Em seguida, serão feitas considerações sobre a incerteza estrutural do direito. O terceiro passo será desenvolver a ideia de racionalidade limitada de Herbert Simon e sua interlocução com os processos decisórios no espaço jurídico. Segue o raciocínio com considerações sobre o argumento das capacidades institucionais e as consequências sistêmicas. Por fim, pretende-se ligar os pontos e sugerir uma abordagem pragmática inspirada no marco teórico de Richard Posner (POSNER, 2010) a partir do reconhecimento de uma meta teoria decisória que traduza uma racionalidade compatível com os cenários reais de tomada de decisão em ambientes de grande incerteza empírica.

\section{RACIONALIDADE IDEAL.}

A revolução provocada pela ascensão da constituição para o centro dos sistemas jurídicos, mormente a partir da normatividade dos princípios, operou uma reaproximação do direito com a moral no pós-guerra e fez brotar diversas teorias normativas que procuraram 
oferecer mais racionalidade para as situações de aplicação do direito, diminuindo a discricionariedade e a subjetividade inerentes ao referido processo.

Teorias pós positivistas ou não positivistas inclusivas, passaram a sustentar novas abordagens hermenêuticas que oferecessem subsídios mais adequados para essa complexa prática social chamada direito.

Ronald Dworkin (DWORKIN, 2010) e Jürgen Habermas (HABERMAS, 1999), entre outros, procuraram construir teorias mais compatíveis com a complexidade do direito em sociedades plurais cujas opções morais não sejam de fácil assimilação. Diante da insuficiência do modelo positivista, mesmo nas versões mais sofisticadas de HART (2010) e KELSEN (1998), os referidos autores desenvolveram modelos que procuraram, cada um à sua maneira, retratar mais adequadamente o processo de produção de um direito legítimo.

As referidas perspectivas põem assento no papel central que ocupa a Constituição, especialmente as normas relativas aos direitos fundamentais, e defendem alguma forma de construtivismo como inerente ao processo de aplicação do direito.

Ideias regulativas como a do Juiz Hércules que visualiza todas as opções decisórias que, a um só tempo, consegue ligar os precedentes, a histórica legislativa e a melhor solução requerida pelo caso, observada a integridade do direito; ou a perspectiva decorrente de um discurso ideal de fala propiciado pela observância das precondições imprescindíveis ao debate livre de coerção para produção do direito legítimo, representam as tentativas mais elaboradas para orientar o intérprete do direito na busca da solução que seja mais correta à controvérsia trazida pelo cenário decisório. Sobre o ponto releva destacar:

\begin{abstract}
...Tanto a teoria Habermasiana do discurso como a teoria da interpretação jurídica de Dworkin são exemplos expressivos de teorias que propõe mecanismos de correção de processos decisórios a partir de modelos ideais, ainda que invistam apenas na maior aproximação possível dos referenciais contrafactuais de que se servem. No primeiro caso, recorre-se a uma concepção ideal de deliberação. No segundo, a um arquétipo sobrehumano de juiz (Hércules). Em ambas as hipóteses, os limites efetivos de implementação de cada teoria, antes de revelarem problemas para aplicações contrafactuais no desenvolvimento de modelos normativos, deixam claro que processos reais de decisão se desenvolvem sob condições não ideais e, não raro, conduzem a resultados subótimos... (LEAL, 2012, p. 28)
\end{abstract}

Tais teorias, não obstante sejam importantes aportes doutrinários para complexas situações envolvendo direitos fundamentais, dizem pouco sobre a maneira de solucionar controvérsias surgidas em um mundo imperfeito que faz ruir, uma por uma, perspectivas 
normativas abrangentes. Diante da limitação cognitiva decorrente da insuficiência de informações, por mais qualificado que seja o debate que antecede a decisão e considerada a velocidade das mudanças empíricas, pretender soluções normativas únicas, baseadas em perspectivas normativas abrangentes, pode não ser a melhor opção.

Embora coerência e integridade sejam pressupostos necessários de qualquer abordagem racional do direito, vez que tais perspectivas iluminam a compreensão de sua natureza e da relação deste com a moral, pouco se aproveita na prática social complexa representada pelos cenários decisórios que lidam com situações subideais e contextos repletos de incertezas, tanto empíricas como normativas.

Quando acionadas para discussões mais concretas, tais teorias acabam por funcionar como reforço retórico de escolhas enviesadas e arbitrárias, pouco sinceras, que retratam escolhas solipsistas e discricionárias, repletas de decisionismo.

A aproximação do direito ao problema a ser solucionado, prestigiando-se uma abordagem interdisciplinar e contextual, pode ser um caminho não para a resposta certa, mas para a resposta menos subjetiva e solipsista. Se incerteza, e algum subjetivismo, é inerente a essa prática social complexa chamada direito, para além dos fundamentos teóricos, urge sejam desenvolvidas abordagens que ofereçam soluções concretas para situações subótimas.

Nesse sentido, na ausência de certeza sobre o contexto empírico em que a decisão será proferida, urge avaliar-se a capacidade institucional dos envolvidos e optar pela solução que seja mais sensata e ofereça as melhores consequências para o conjunto da sociedade.

$\mathrm{O}$ direito pátrio exige que o magistrado decida as questões que lhe são postas, art.140 da Lei 13.256/16 (Código de Processo Civil, CPC). Entretanto, tal fato não significa que o magistrado tenha sempre que ser o autor da melhor solução. Tal dispositivo é compatível com uma postura deferente e que reconheça a maior capacidade institucional de outra opção decisória, ensejando uma decisão que confirme a solução mais sensata e que provoque os melhores efeitos sistêmicos.

Nesse ponto, sustenta-se que a LINDB adotou um consequencialismo fraco (SWARTZ, 2008) instando o juiz a buscar a solução correta. Mas, diante da multiplicidade de opções racionalmente sustentáveis, deve o decisor optar pela que produza os melhores efeitos sistêmicos e, em caso de dúvida, agir com deferência para com o interessado que apresente maior capacidade institucional para elaborar e monitorar políticas públicas, tais como as que definem a medida restritiva de deambulação. 


\section{INCERTEZA E RACIONALIDADE LIMITADA.}

A partir da noção corrente de que texto e norma são coisas distintas e que o fenômeno jurídico resulta de uma complexa prática social que envolve textos, precedentes, agentes, tradições, instituições, consequências, contexto e interpretações, a insuficiência do material proveniente das fontes formais é algo intuitiva.

Assim, há uma incerteza estrutural do direito contra a qual não há solução ou abordagem hermenêutica que consiga romper a ligação das normas ao intérprete. Decisores reais estão sujeitos às suas contingências.

O prêmio Nobel de economia Herbert Simon (SIMON, 1955) desenvolveu uma perspectiva que veio demonstrar a insuficiência da ideia de um homo economicus que decidisse sempre a partir da ideia de maximização de utilidade. Na perspectiva tradicional em economia, modelos idealizados abstratos sobre como as pessoas decidem eram a opção default. Nesse sentido, destaca-se passagem doutrinária que ilustra o ponto:

\footnotetext{
...Por meio da expressão "racionalidade limitada", Simon pretendia sintetizar o insight de que pessoas se servem de mecanismos simplificadores ou "atalhos" quando tomam decisões que frequentemente resultam em escolhas que não maximizam as suas utilidades individuais. O ponto de Simon é que as potencialidades da teoria econômica se reduzem drasticamente quando se pensa em organismos reais que precisam tomar decisões em certos ambientes. Nas palavras de Luhmann "ele estabelece que o modelo de decisão do agir econômico otimizador sobrestima as capacidades humanas a considerações racionais e é, por isso, irrealista, ou seja, não verificável empiricamente. (...) Pessoas comuns estão rodeadas por constrangimentos internos (físicos e psíquicos) e externos (frutos da interação com o ambiente e com outros seres) que interferem nos seus processos decisórios. Alguns elas podem controlar (i.e. otimizar), outros não. Algumas características físicas (como mortalidade) já são suficientes para justificar por que o tempo é, por exemplo, necessariamente um recurso escasso e por que vencer distâncias e barreiras físicas pode ser um processo bastante custoso. Essas limitações criam uma dimensão de incerteza inafastável em qualquer processo de tomada de decisão, já que a obtenção de qualquer informação, ao menos, no curto prazo, torna-se necessariamente custosa. O problema da incerteza já seria, assim, um argumento forte contra a onipotência de um juiz real. Mas ao lado dela, há ainda limitações próprias do modo humano de entender e usar as informações disponíveis. Há, em outras palavras, uma limitação associada à capacidade de processamento dessas informações, que é conhecida como problema da racionalidade limitada. Se esse argumento é de se levar a sério, então é possível dizer que, por definição, "juízes, como outros tomadores de decisão, nunca são completamente racionais...(LEAL, 2012, p.39)
} 
Conforme a lição destacada, decisores reais possuem racionalidade limitada, é dizer, capacidade insuficiente para colher e processar todas as informações relevantes, em um período de tempo insuficiente, para resolver questões jurídicas complexas.

Somados, a incerteza estrutural do direito e a racionalidade limitada dos decisores, ensejam mecanismos de controle da argumentação, é dizer, das razões que fundamentam determinada opção decisória em cenários desconhecidos, como os decorrentes das opções de política sanitária durante o período pandêmico.

Uma vez reconhecidas as limitações dos decisores e as dificuldades decorrentes da própria noção de direito, urge buscarem-se soluções subótimas que trabalhem melhor as informações disponíveis, levando-se em conta o contexto decisório, a capacidade institucional dos interessados, as particularidades do caso e a melhor abordagem meta teórica para a questão posta perante o decisor. Tais opções são as que estão ao alcance do decisor. Sobre o ponto destaca-se:

...Dado que o ambiente decisório no qual as decisões tem que ser tomadas caracteriza-se
por complexidade e incerteza "forte" (hard uncertainty), deixa simplesmente de ser racional
o comportamento marcado pela busca da solução ótima (ou seja, maximizadora) e passa a
ser racional a adoção de rotinas, estratégias e padrões de comportamento relativamente
estáveis (embora, de maneira alguma necessariamente conservadora, uma vez que podem
estar intencionalmente direcionados à obtenção de resultados inovadores e criativos, como
é o caso da rotinização e padronização de esforços em P\&D nas grandes empresas). Sob
tais condições, a univocidade da solução ótima cede passo à multiplicidade e
heterogeneidade das soluções subótimas ou - para usar uma expressão neutra em relação à
existência pressuposta da solução ótima - satisfatórias (satisficing), na famosa expressão de
Simon... (SCHUARTZ, 2005, p. 200).

Para ilustrar o ponto, no contexto brasileiro, decisões sobre as medidas restritivas deambulatórias durante o início da pandemia do coronavírus foram expedientes adotados pela maioria dos gestores públicos para conter a disseminação do vírus. Com efeito, grande parte de tais decisões acabaram sendo judicializadas e liminares em todos os sentidos foram proferidas. Não obstante o contexto de incerteza empírica, o Supremo Tribunal Federal (STF), na Ação Direta de Inconstitucionalidade n. 6.341 do Distrito Federal, foi firme no sentido de que os gestores públicos deveriam ter autonomia para decidirem qual o melhor caminho a seguir, a partir da situação pandêmica local, desde que as medidas obedecessem ao postulado da necessidade (ALEXY, 2010) e estivessem fundadas no conhecimento científico disponível acerca de tais questões sanitárias. 
A opção do STF foi pela deferência às escolhas informadas dos gestores nos casos em que as medidas sanitárias estivessem baseadas nas informações científicas disponíveis e o contexto impusesse tais medidas.

Sustenta-se que o STF agiu acertadamente neste cenário de relativa incerteza empírica. Com efeito, não só reconheceu sua incapacidade para fixar uma resposta abrangente e definitiva sobre a validade de todas as medidas restritivas deambulatórias, mas reconheceu que os limites cognitivos, a ausência de informação e de tempo, impunham deferência para escolhas elaboradas pelos diversos comitês sanitários que se formaram para fazer face à pandemia.

O contexto pandêmico é volúvel e oscila de uma semana para outra. Decisões abrangentes e para todos os cenários decisórios não são respostas racionais para a crise sanitária. Trata-se de uma reserva administrativa a ensejar soluções concretas observada a necessária cadeia normativa e a capacidade institucional dos comitês para oferecer soluções em cenários de grande incerteza empírica.

\section{MARGENS DE ATUAÇÃO DOS DECISORES.}

Embora a teoria dos princípios e a teoria da argumentação jurídica configurem tentativas de redução do subjetivismo dos decisores, a importação descuidada de teorias abrangentes para o ambiente decisional pátrio, somada à banalização da utilização de princípios abstratos com a consequente obliteração de regras claras e que oferecem escolhas sensatas, a pretexto de concretizar direitos fundamentais, vêm provocando um efeito sistêmico negativo.

Cenários de incerteza propiciam opções decisórias enviesadas (KANEMAN, 2018) e intuitivas. Optar pela deferência e por técnicas de desenviesamento, pode ser uma opção decisória pragmática e que traduza o consequencialismo moderado pretendido pela reforma da Lei de introdução às normas do Direito Brasileiro (LINDB), Decreto-Lei n. 4.657, de 4/09/1942.

Com efeito, a desconsideração das capacidades institucionais de outros agentes públicos nas decisões concretizadoras de direitos retratam certa cegueira institucional (LEAL, 2016) provocando um descolamento entre o direito e a realidade, ensejando a prolação de 
decisões bem-intencionadas, mas inexequíveis, dificultando o avanço de políticas públicas necessárias ao cumprimento das promessas constitucionais.

É certo que o direito não se destina apenas a corrigir falhas de eficiência. O limite de abordagens pragmáticas é o limite do que é inegociável, ainda que seja economicamente ineficiente.

Entretanto, mesmo em discussões que envolvem a delimitação de Direitos fundamentais, os cenários decisórios são essenciais para qualquer modelagem decisória de provimentos judiciais. Olhar o contexto e considerar opções que tragam melhores consequências sistêmicas é um dever de todo magistrado, para além da proteção de direitos.

Consequências sistêmicas a serem consideradas pelos decisores são as que repercutem em um espectro amplo de outros casos, seja por mimetismo, seja por adaptação. Colhe-se lição doutrinária que melhor explica o argumento:

\begin{abstract}
...Os erros indiretos são frutos dos chamados "efeitos sistêmicos", que podem ser "efeitos sistêmicos miméticos" ou "efeitos sistêmicos de adaptação". Um juiz ou um grupo de juízes pode se desviar de certas regras claras para aplicar princípios em certos casos de forma correta. Todavia, isso pode contar como um estímulo para que juízes não tão sábios e preparados queiram imitá-los. Os juízes que adotam o comportamento mimético, por não serem preparados, acabam cometendo uma grande quantidade de erros ou erros muito severos. Esses são os chamados "efeitos sistêmicos miméticos". Os efeitos sistêmicos de adaptação, por sua vez, ocorrem quando agentes não judiciais, percebendo os desvios constantes dos juízes que estão aplicando princípios e deixando de lado as regras, acabam tentando se adaptar de maneira subótima. Isso ocorre, por exemplo, quando uma política pública de vacinação que poderia prevenir uma doença séria em milhares de pessoas não é realizada porque o governo resolve usar a parte do orçamento destinado para a implementação da política pública em um fundo reserva para o pagamento de caríssimos remédios que são demandados por um grupo menos expressivo de pessoas no judiciário... (STRUCHINER; SHECAIRA, 2012, p.143).
\end{abstract}

A preocupação com a interferência na realidade e as consequências extrajurídicas não é novidade no direito processual. A suspensão de liminar, art. $4^{\circ}$ da Lei 8.437/92 e a repercussão geral, art. 1035 do CPC são exemplos de consideração de consequências sistêmicas muito além dos interesses das partes do processo.

Nesse sentido o art. 20 e art. 21 do LINDB, com a redação determinada pela Lei 13.655/18, somada à disposição do art. 489, $\$ 1^{\circ}$, II do CPC completam o quadro de inclinações pragmáticas no direito pátrio.

Nessa perspectiva, a multiplicidade de decisões baseadas em teorias abrangentes descoladas da realidade provocou uma reação legislativa a partir da perspectiva pragmática do 
direito. Um dos autores do diploma que modificou a LINDB retratava o quadro como tintas fortes, destaca-se:

\begin{abstract}
...Vive-se hoje um ambiente de "geleia geral" no direito público brasileiro, em que princípios vagos podem justificar qualquer decisão. O objetivo deste ensaio é opor-se a essa deterioração da qualidade do debate jurídico. O profissional do direito, ao construir soluções para os casos tem um dever analítico. Não bastam boas intenções, não basta intuição, não basta invocar e elogiar princípios; é preciso respeitar o espaço de cada instituição, comparar normas e opções, estudar causas e consequências, ponderar as vantagens e desvantagens. Do contrário viveremos no mundo da arbitrariedade, não do direito. (...) Como não há fundamento algum para a presunção absoluta de que é do judiciário, e não de outros órgãos, a competência para construir soluções jurídicas específicas a partir de princípios, sua intervenção em cada caso depende de elementos especiais de ordem institucional que a justifiquem, e eles têm de ser identificados pela decisão (ônus da competência). Ademais a simples pertinência do princípio ao caso não é bastante para justificar a solução específica, sendo indispensável formular de modo explícito a regra geral que se vai aplicar, justificando-a com a análise profunda das alternativas existentes, de seus custos e, ainda, de seus possíveis efeitos positivos e negativos (ônus do regulador)... (SUNDFELD, 2017, p.205)
\end{abstract}

Decisões sobre restrições de deambulação implicam sempre na interferência da situação de pessoas que não fazem parte do processo, não constituíram advogado e não tiveram suas perspectivas discutidas em um contraditório qualificado.

Não obstante os citados exemplos, que são devidamente regulados por textos legais, a obrigação de considerar as consequências sistêmicas dos provimentos judiciais é algo trivial e uma prática comum entre magistrados de todos os tribunais.

O direito é uma prática social complexa (DWORKIN,2010), que envolve essencialmente textos, aspectos institucionais, valorações, ideologias, agentes, argumentação, fatos, contexto e, sempre, alguma dose de subjetivismo.

Para piorar, a economia comportamental vem comprovando que a subjetividade dos decisores é impregnada de vieses cognitivos (NUNES, 2020). A dominância de uma teoria normativa que albergue toda a complexidade do direito, que seja indene de críticas e que promova ao mesmo tempo os ideais de permanência e mudança requeridos pela CRFB/88 é um desafio que remete mais a Sísifo do que a Hércules.

Talvez seja melhor descer alguns degraus no nível de abstração e tentar-se uma metateoria normativa para decisões judiciais que possam traduzir uma reflexão qualificada e resulte não em um consenso, mas em um provimento que possa ser aceito pela maioria das pessoas implicadas na discussão e que ofereça uma solução sensata para o problema. 
Se não há uma margem fixa de atuação, há que se procurar critérios racionais para escolhas em ambientes de incerteza empírica a partir da análise das capacidades institucionais e dos elementos concretos colacionados ao processo.

Uma perspectiva aintifundacionalista, que prestigie o contexto e que leve em consideração as consequências sistêmicas, em suma, uma atitude pragmática do direito (POSNER, 2012) é a atual diretiva normativa e medida que se impõe.

Sempre bom lembrar não ser o pragmatismo incompatível com o formalismo. Trata-se de uma técnica decisional de segunda ordem. Consequentemente, se houver um cenário de incerteza empírica e uma solução mais próxima do texto que seja razoável, a postura pragmática recomendará a adoção de tal perspectiva, já que trará melhores consequências sistêmicas (LEAL, 2021).

Para Manuel Atienza (ATIENZA, 2014) o pragmatismo também é compatível com teorias não positivistas ou pós positivistas. Em sua perspectiva, caso não se sustente um relativismo axiológico e não se identifique correção com eficiência, bem como, por outro lado, rejeite-se uma concepção demasiadamente abstrata do direito, poder-se-á agrupar um universo diversificado de autores em um grande guarda-chuva pragmático. Destaca-se:

...O pragmatismo, em relação ao direito, parece supor a aceitação de teses como as seguintes (vid. Posner, 90; Smith, 1990): 1) A necessidade de considerar o Direito e só problemas jurídicos relacionados ao contexto; 2) Ter em conta (se quisermos, como consequência do anterior) que as teorias, ou as doutrinas, são elaboradas com o propósito de se dirigirem a um determinado auditório. 3) A rejeição de uma concepção demasiado abstrata do Direito; não significa que se esteja contra os conceitos ou as teorias, mas que uns e outras devem ser elaborados como o nível de abstração adequado. 4) Uma visão instrumental e finalista do Direito; o Direito é um instrumento para resolver (ou prevenir, ou tratar) conflitos, um meio para obtenção de fins sociais; o que não é razão para excluir que possa existir algo assim como "fins internos", próprios do Direito. 5) A vinculação do Direito a certas necessidades práticas dos homens. 6) A ênfase que se põe nas consequências, no futuro; o que tão pouco exclui que se tome em consideração o passado, mas sem que este seja valorado por si mesmo, e não pela sua contribuição para que este seja valorado por si mesmo, e não pela sua contribuição para a obtenção de certos resultados futuros. 7) A ideia de que a verdade (pelo menos no campo da prática) não consiste na correspondência dos enunciados com o mundo, mas que esses enunciados resultem úteis, e daí a importância do diálogo e do consenso como critério de justificação; 8) A importância da prática como meio de conhecimento: apreende-se a argumentar, argumentando, etc... (ATIENZA, 2014, p74)

Desse modo, tanto para o referido autor quanto para Posner (POSNER, 2010), pragmatismo no direito seria uma atitude, uma maneira de resolver os problemas com o foco na solução mais sensata e razoável. 
O direito destina-se a resolver conflitos por meios argumentativos. Dessa maneira, sem desconsiderar a pretensão de correção, deve-se buscar opções que respeitem a integridade ou a coerência do direito, mas que ofereçam soluções subideais para problemas concretos.

Há um longo caminho a ser percorrido na concretização das promessas constitucionais que vão tirar o Brasil de sua modernidade tardia. Mas esse processo envolve todos os poderes em uma atuação dialogada e que leve a sério as capacidades institucionais dos envolvidos, bem como o contexto em que cada decisão será proferida. Garantir direitos e impulsionar o espaço majoritário a proferir decisões dentro da gramática constitucional são abordagens promissoras.

Lado outro, reconhecer que nem sempre há um caminho claro a seguir e que a CRFB/88 não provê solução para todas as controvérsias, antes, distribui competências a diversas instâncias decisórias, parece um caminho alvissareiro para uma modelagem decisória que respeite direitos fundamentais, mas que se aproveite de abordagens empíricas, quando forem úteis e trouxerem informações relevantes sobre os impactos regulatórios.

\section{CAPACIDADE INSTITUCIONAL.}

A CRFB/88 não pretendeu engolfar toda a realidade circundante. Nem toda questão jurídica vai desafiar o desenvolvimento de um aprofundado questionamento de moralidade política para apontar a solução mais correta e que represente a necessária integridade e coerência da ordem jurídica.

Para além de direitos fundamentais, pretendeu o constituinte limitar o poder político dividindo a competência para a realização das promessas constitucionais entre diversos atores institucionais. Com efeito, no plano abstrato, ideal, caberia ao congresso atuar na formulação de normas abrangentes e genéricas, dentro da gramática constitucional, é dizer, observados os limites epistêmicos e estruturais de sua atuação (ALEXY, 2010). Ao executivo caberia atuar de acordo com a juridicidade (BINENBOJM, 2010) concretizando e fazendo escolhas dentro de sua margem de atuação. Por fim, caberia ao Poder Judiciário garantir direitos e impulsionar o espaço majoritário a agir, nos casos de omissão.

O quadro acima retratado, embora seja familiar e intuitivo para os aplicadores do direito, é uma idealização da divisão abstrata dos poderes, que nada tem a ver com a ideia de capacidades institucionais. Colhe-se lição doutrinária que ressalta o ponto: 


\begin{abstract}
...Assim, o raciocínio pressuposto pelo argumento de "capacidades institucionais" poderia ser sintetizado a partir das seguintes características: uma comparação empiricamente informada sobre os custos e benefícios de se alocar, no agregado, a prerrogativa de resolução de um determinado problema a uma determinada instituição dentre várias instituições possíveis. Esse cenário, como se vê, não comporta escolhas entre instituições feitas em abstrato... (LEAL; ARGUELHES, 2016, p. 198)
\end{abstract}

A capacidade institucional envolve o contexto decisório, os elementos empíricos disponíveis e uma pluralidade de órgãos, instituições e os poderes da república. Nesse sentido, a discussão relevante e a contribuição que tal perspectiva oferece é a da análise do cenário decisório complexo e das assimetrias de conhecimento.

O STF já teve oportunidade declarar inconstitucional a Lei 13.269/2016 que obrigava os estados da federação a fornecerem a substância fosfoetanolamina na Ação direta de Inconstitucionalidade (ADI) 5.501, forte em que, no caso específico, a Agência Nacional de Vigilância Sanitária (ANVISA) teria mais capacidade institucional para regulamentar a matéria.

Em outro caso paradigmático, o STF, ao analisar o Agravo Regimental em Mandado de Segurança n. 36.869 do Distrito Federal, acolheu o pedido, mas determinou que a própria Corte de Contas, impetrada, refizesse os cálculos a partir dos parâmetros fixados no julgamento, em razão da sua maior capacidade institucional para levar a efeito tal tarefa.

Do exposto, conclui-se que analisar a capacidade institucional dos envolvidos no processo não é novidade no direito brasileiro e revela postura deferente, que admite a racionalidade limitada e a incerteza estrutural do direito, bem como reconhece que há um sistema constitucional de competências que deve ser aferido no plano concreto, caso a caso, para que se defina a margem de atuação dos interessados.

\title{
5. CONCLUSÃO.
}

O presente artigo pretendeu retratar com mais fidedignidade as dificuldades decorrentes da racionalidade limitada de decisores reais em cenários de grande incerteza empírica. Para tanto, partiu-se da perspectiva que corresponde ao mainstrean em matéria de solução dos casos difíceis que correspondem a uma racionalidade idealizada para oferecer soluções supostamente mais legítimas e adequadas. 
A perspectiva de uma racionalidade ideal não consegue oferecer subsídios para a diversidade de cenários decisórios que exigem análise de circunstâncias fáticas de difícil assimilação e que se alteram rapidamente. Nesse espaço de atuação, deve-se deferência às instituições com maior capacidade institucional para processar informações e sopesar as consequências sistêmicas.

A postura deferente não fragiliza o direito, torna-o mais complexo, vez que reconhece sua incerteza estrutural, bem como a racionalidade limitada dos decisores reais e que tendem a proferir decisões enviesadas e abrangentes.

Tal como destacado por Stephen Holmes (HOLMES, 2009), em cenários de incerteza, embora haja espaço para escolhas mais dinâmicas e particularizadas, há sempre um protocolo a seguir. Com efeito, e no caso de decisões proferidas no cenário pandêmico, há uma cadeia normativa que estrutura o direito sanitário no qual concorrem normas federais, estaduais e municipais, bem como existem comitês técnicos que acompanham a evolução das medidas sanitárias e monitoram as consequências das políticas adotadas.

Sustentou-se, então, a contribuição que a inclinação pragmática do direito brasileiro pode oferecer. Nesse sentido, diante de um cenário de poucas informações disponíveis, da falta de elementos empíricos que traduzam as consequências sistêmicas das opções decisórias e de assimetria cognitiva entre especialistas e o Judiciário, deve-se optar por uma postura formalista ou particularista, a depender dos custos do erro relativos a cada opção decisória.

Destacou-se que o argumento das capacidades institucionais não deve ser tratado de forma abstrata. O texto constitucional que retrata o sistema de competências contém, de maneira impressionista, esfumaçada, margens de atuação para as diversas funções estatais. Mas é no caso concreto que se observará quem poderá oferecer a melhor resposta para cenários de incerteza empírica. Não é a realidade que deverá se ajustar ao texto elaborado em 1988, tal como se este fosse uma cama de Procusto.

A realidade é dinâmica, e o direito deve ser também. Dizer que há uma margem de atuação para decisores, a depender do contexto e de cada cenário decisório, não significa adotar-se um direito alternativo, uma postura realista, ou mesmo um particularismo como regra-geral, mas reconhecer que, na dupla dimensão do direito convivem um aspecto estrutural e outro ideal, sendo certo que há uma tensão a provocar inevitável cenário de flexibilidade hermenêutica, que a teoria dos princípios, a teoria da argumentação e um consequencialismo fraco pretendem delimitar. 
Se não é possível separar a norma do intérprete, por melhor que seja o debate e as razões apresentadas, que se busque, a partir da racionalidade limitada e da incerteza estrutural do direito, a melhor maneira de reduzir o subjetivismo na direção da objetividade possível.

\section{REFERÊNCIAS BIBLIOGRÁFICAS.}

ALEXY, Robert. Conceito e Validade do Direito. São Paulo: Martins Fontes, 2009.

ALEXY, Robert. Teoria Discursiva do Direito. Rio de Janeiro: Forense, 2019.

ALEXY, Robert. Teoria da Argumentação Jurídica: Teoria do discurso racional como teoria da fundamentação jurídica. Rio de Janeiro: Forense, 2011.

ATIENZA, Manuel. O sentido do Direito. Lisboa: Escolar Editora, 2012.

ATIENZA, Manuel. O Direito como Argumentação. Lisboa: Escolar Editora, 2014.

BARROSO, Luis Roberto. Curso de Direito Constitucional Contemporâneo - $9^{\mathrm{a}}$ edição São Paulo: Saraiva Educação, 2020.

BINENBOJM, Gustavo. Uma teoria do Direito Administrativo: direitos fundamentais, Democracia e Constitucionalização. Rio de janeiro: Renovar, 2008.

BRASIL. Constituição (1988) Constituição da República Federativa do Brasil. Disponível em http://www.planalto.gov.br/ccivil_03/Constituicao/Constituicao.htm, acesso em 16/4/2021.

BRASIL. Lei $\mathbf{n}^{0}$ 13.105, de 16 de março de 2015. Institui o Código de Processo Civil. Diário Oficial da União, Brasília, DF, 17 março 2015. Disponível em https://www.planalto.gov.br/ccivil_03/_ato2015-2018/2015/lei/113105.htm.

BRASIL. Decreto-Lei n.4.657, de 4 de Setembro de 1942. Disponível em: http://www.planalto.gov.br/ccivil_03/decreto-lei/del4657.htm, acesso em 16/4/2021.

BRASIL. Ação direta de inconstitucionalidade 6341/Distrito Federal Min. Dias Toffoli, DJE, 12/11/2020.

BRASIL. Ação direta de inconstitucionalidade 5.501/Distrito Federal. Relator Min. Marco Aurélio, DJE,30/11/2020.

BRASIL. Agravo regimental em mandado de segurança n. 36.869/Distrito Federal. Relator Min. Fux. DJE,30/11/2020 
DWORKIN, Ronald. Levando os Direitos a Sério - São Paulo: editora WMF Martins Fontes, 2010.

HABERMAS, Jürgen. Direito e Democracia: entre faticidade e validade. Vol.1 e 2.

Tradução: Flávio Beno Siebeneichler - Rio de Janeiro: Tempo Brasileiro, 2010.

HART, Herbert Lionel Adolphus. O conceito de Direito - São Paulo: WMF Martins Fontes, 2009.

HOLMES, Stephen. In case of Emergency: Misunderstanding Tradeoffs in the War on Terror. California Law Review, vol. 97, n.2, pp. 301-356, 2009. Disponível em SSRN: https://ssrn.com;abstract=1495769

KANEMAN, Daniel. Rápido e Devagar: duas formas e pensar - São Paulo: Objetiva, 2012.

KELSEN, Hans. Teoria Pura do Direito - São Paulo: Martins Fontes, 1998.

LEAL, Fernando. "A Constituição diz o que eu digo que ela diz: Formalismo inconsistente e textualismo oscilante no direito constitucional brasileiro. Revista Direitos Fundamentais \& Justiça - ano 11, n. 36, jan./jun.2017 - Belo Horizonte: Fórum, 2017.

LEAL, Fernando; ARGUELHES, Diego Werneck. Dois problemas de operacionalização do argumento de "capacidades institucionais". Revista de Estudos Institucionais, v. 2, 1, 2016.

LEAL, Fernando. ARGUELHES, Diego Werneck; LEAL, Fernando. O argumento das "capacidades institucionais" entre a banalidade, a redundância e o absurdo. Revista Direito, Estado e Sociedade, n. 38, 2011.

LEAL, Fernando. Ônus de argumentação, relações de prioridade e decisão jurídica: mecanismos de controle e de redução da incerteza na subidealidade do sistema jurídico. Tese apresentada ao Programa de Pós-graduação da UERJ. Rio de Janeiro. Disponível em: https://bdtd.ibict.br/vufind/Record/UERJ_1e20cebde5f51f7079380198fafb4311.

LEAL, Fernando et alii. Pragmatismo como (Meta) Teoria Normativa da Decisão Judicial: Caracterização, estratégias e implicações. Rio de Janeiro: Lumen juris, 2009.

MELO, Tatiana Massaroli et ali. Racionalidade limitada e a tomada de decisão em sistemas complexos. Revista de Economia Política, v. 36. Disponível em http://dx.doi.org/10.1590/0101-31572016v36n03a09.

NUNES, Dierle; PEDRON, Flávio Quinaud; LUD, Natanael. Desconfiando da Imparcialidade dos sujeitos processuais: um estudo sobre os vieses cognitivos, a mitigação de seus efeitos e o debiasing - Salvador: Editora JusPodivm, 2020.

PEREIRA, Jane Reis Gonçalves. Interpretação constitucional e direitos fundamentais São Paulo: Saraiva Editores, 2018.

POSNER, Richard. Direito Pragmatismo e democracia. Rio de Janeiro: Forense, 2010.

Teorias do Direito e Realismo Jurídico | e-ISSN: 2525-9601 | Encontro Virtual | v. 7 | n. 2 |

p. $01-17$ | Jul/Dez. 2021. 
REIS, Paulo Marcio. Umbrella effects e a repressão a carteis no Brasil: análise sob a ótica do private enforcement. Tese de doutoramento apresentada ao Programa de Pos-Graduação da Faculdade de Direito da Universidade de Minas Gerais. Belo Horizonte, 2019.

SCHUARTZ, Luis Fernando - Norma, Contingência e racionalidade - Rio de Janeiro: Renovar, 2005.

SCHUARTIZ, Luis Fernando. Consequencialismo Jurídico, Racionalidade Decisória e Malandragem. Revista De Direito Administrativo, 248, 130-158.

https://doi.org/10.12660/rda.v248.2008.41531

SIMON, Herbert. A Behavioral Model of Rational Choice. The Quertely Journal of Economics, v. 69, n.1, pp. 99-118. Disponível em: http://www.jstor.org/stable/1884852.

STRUCHINER, Noel; SCHECAIRA, Fábio P. Teoria da Argumentação jurídica - Rio de Janeiro: Editora PUC-Rio: Contraponto, 2016.

STRUCHINER, Noel; SCHECAIRA, Fábio P. A Distinção entre Direito e Moral e a distinção Moral do Direito. Revista de Direito do Estado. Ano. 7, n.22, pp. 131-145. Rio de Janeiro, 2012.

SUNDFELD, Carlos Ari. Direito Administrativo pra Céticos. 2a edição - São Paulo: Malheiros editores, 2014. 